\title{
Reflexões sobre o fazer pedagógico nas aulas de Educação Física do Ensino Médio
}

\author{
Márcia Cristina Rodrigues da Silva Coffani ${ }^{1}$ \\ ORCID: 0000-0002-5008-3380 \\ Cleomar Ferreira Gomes ${ }^{1}$ \\ ORCID: 0000-0003-0451-1011
}

\section{Resumo}

0 trabalho discute as investigações acerca das práticas curriculares e pedagógicas do fazer pedagógico em educação física no ensino médio. As discussões teóricas e metodológicas têm assento na Sociologia do corpo, do cotidiano e da juventude. 0 estudo é qualitativo, etnográfico-descritivo e teve como sujeitos de pesquisa o professor e jovens alunos participantes das aulas de educação física, em uma escola pública estadual, em CuiabáMT. Envolveu análise de fontes documentais como Projeto Pedagógico da Escola e Planejamento Anual de Ensino da Educação Física; observações participantes das aulas e do cotidiano da escola; entrevistas semiestruturadas com professor e jovens alunos. A partir do conhecimento de aspectos do universo juvenil, em específico, os marcadores sociais que permeiam as relações e condições materiais, culturais e simbólicas de vida dos participantes se pode refletir a juventude como categoria sociocultural e a relação da escola e a educação física com o contexto de vida dos jovens. Avaliaram-se as ausências e presenças de sentidos das aulas de educação física para reflexão do seu lugar no projeto de formação cultural das juventudes. Sugerem-se possibilidades de práticas pedagógicas que valorizem o ensino das práticas corporais a partir da aproximação com o universo juvenil, o que é necessário para que ocorra a legitimidade e autonomia pedagógica da disciplina no currículo do ensino médio.

\section{Palavras-chave}

Juventudes - Educação Física - Ensino Médio.

1- Universidade Federal de Mato Grosso (UFMT); Cuiabá, Mato Grosso, Brasil. Contatos: marciacoffani@hotmail.com; gomescleo.cg@gmail.com

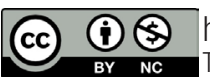




\section{Reflections on teaching practice in high school physical education classes}

\section{Abstract}

The work discusses the investigations about the curricular practices within the pedagogical teaching in physical education in high school. Theoretical and methodological discussions are based on the Sociology of the body, everyday life and youth. The study is qualitative, ethnographic-descriptive and the research subjects were the teacher and young students participating in physical education classes, in a public school, in Cuiabá-MT. It involved analysis of documentary sources such as the School's Pedagogical Project and Annual Physical Education Teaching Plan; participant observations in classes and in the daily life of the school; semi-structured interviews with teacher and young students. Based on the knowledge of aspects of the youth universe, particularly the social markers that permeate the material, cultural and symbolic relationships and conditions of life of the participants, youth can be reflected as a sociocultural category and the relationship of school and physical education within the context of young people's lives. The absence and presence of meanings in physical education classes were evaluated to reflect on their place in the cultural training project for young people. Possibilities of pedagogical practices that value the teaching of body practices stemming from the approximation to the youth universe are suggested, which is necessary for the legitimacy and pedagogical autonomy of the discipline to occur in the high school curriculum.

\section{Keywords}

Youth - Physical Education - High School.

\section{Introdução}

Este trabalho é um diálogo sobre relações, desafios, concepções e possibilidades do fazer pedagógico para o ensino das práticas corporais para juventudes a partir da investigação das práticas curriculares e pedagógicas implementadas por professores de educação física (EF), em esforço da desejável legitimidade e autonomia da disciplina no ensino médio (EM). Tal esforço requer compreender o universo de socialização do jovem, ao superar análises focalizadas unicamente na condição de aluno, restringindo-se aos muros escolares, sem abarcar as "[...] múltiplas dimensões da sua experiência escolar" (DAYRELL et al., 2009, p. 106).

As reflexões teóricas e metodológicas acerca das possibilidades do fazer pedagógico foram produzidas com base na compreensão sensível e relativista das rotinas e práticas curriculares e pedagógicas (re)produzidas em uma escola da rede de ensino público estadual 
de Cuiabá-MT, a partir da descrição dos usos dos tempos e espaços que organizam a cultura escolar, em que interessaram os (des)encontros das práticas pedagógicas em EF (Educação Física) com os jovens alunos do EM.

As discussões têm assento na Sociologia do corpo, do cotidiano e da juventude, que valoriza a concepção da diversidade de juventudes, reconhece a existência de múltiplos projetos educativos que atendem aos jovens alunos e as singulares intenções pedagógicas que ordenam a cultura ordinária escolar.

0 texto vale-se do acumulado no debate acadêmico produzido, em especial, pela EF escolar, que registra práticas pedagógicas inovadoras aprendidas no chão da escola, com a intenção de contribuir com a docência, o fortalecimento da identidade profissional docente e o estado de legitimidade da EF no EM (COFFANI et al., 2018; ALMEIDA, 2017; BUNGENSTAB, 2017; FENSTERSEIFER; SILVA, 2011; TABORDA DE OLIVEIRA, 2008).

Situa-se este estudo no conjunto de produções científicas dedicadas a estimular leituras e debates sobre as relações da EF com os jovens alunos do EM, em que se considerem as contraditórias condições juvenis de se viver essa fase do ciclo da vida, para assim, refletir possibilidades do fazer pedagógico nas aulas de EF do EM.

\section{Metodologia}

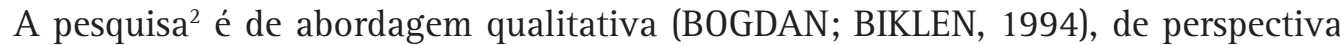
etnográfico-descritiva (FONSECA, 1999; LÜDKE; ANDRÉ, 1986), e voltou-se à investigação das práticas, saberes e fazeres curriculares e pedagógicos implementados nas aulas de EF no EM, em uma escola pública estadual, situada na zona urbana, do município de CuiabáMT, durante os segundos e terceiros bimestres letivos do ano de 2016.

A escola campo de pesquisa é uma tradicional instituição educativa que foi construída para ser escola modelo nos anos de 1970 frente ao processo de ocupação da fronteira norte do estado de Mato Grosso. É símbolo de qualidade, de organização políticopedagógica e de engajamento em ações de mobilização estudantil, assim reconhecida pela comunidade cuiabana.

A pesquisa privilegiou a escuta do professor e jovens alunos do EM, envolvendo a análise de fontes documentais como Projeto Pedagógico e Planejamento de Ensino Anual de EF; entrevistas semiestruturadas realizadas individualmente com 16 alunos/ as do EM participantes assíduos das aulas de EF e o professor, gravadas em áudio e com transcrição íntegra das falas sobre perfil socioantropológico da condição juvenil, a relação de sentido com a escola e a EF e da EF extraespaço escolar e observações participantes do cotidiano da escola, realizadas semanalmente durante o período de abril a setembro de 2016, com base em roteiros orientadores sobre o contexto da escola (caracterização da escola; organização do ensino; planejamento das atividades

\footnotetext{
2- A participação foi respaldada por Termo de Livre Consentimento e Esclarecido (TCLE), aprovado pelo Comitê de Ética em Pesquisa e registrado na Plataforma Brasil/CONEP, sob o nº. CAAE 03256312.5.0000.5541, de cada escola, professores e jovens alunos.
} 
curriculares e extracurriculares desenvolvidas pela escola) e das aulas de EF no EM (descrição da aula e as relações no contexto da aula), acompanhadas pelo registro de imagens e filmagens de suas rotinas e práticas culturais juvenis e suas relações com o corpo e práticas corporais vivenciadas nas aulas de EF, das turmas Primeiro Ano J e I - Técnico em informática; Primeiro Ano K - Técnico em administração; Segundo ano K - Técnico em administração; Primeiro ano K; Terceiro ano F e Terceiro ano E.

0 processo de triangulação dos dados, característico de pesquisas de inspiração etnográfica, permitiu conhecer aspectos do universo juvenil desses jovens alunos, com destaque aos marcadores sociais que permeiam as relações e condições materiais, culturais e simbólicas de vida desses jovens na sua condição estudantil, que são importantes elementos para compreensão da juventude como categoria sociocultural e a avaliação reflexiva das relações dos projetos pedagógicos com o ensino da EF no EM e o contexto de vida dos jovens.

\section{Relações da EF com o jovem aluno do EM}

A compreensão do cotidiano da EF no EM e as relações de sentidos que tece com o jovem aluno é complexa, pois é preciso considerar que a ação pedagógica do professor é influenciada por fatores organizacionais, sociopolíticos e culturais, de modo que o ato de ensinar não ocorre desvinculado das características da sociedade na qual a escola se insere (CAPARROZ, 1997).

0 estudo notou que há um empenho da escola em oferecer a aula mista de EF do EM no horário regular de aula com impacto sobre a redução do número de alunos dispensados das aulas em função da Lei n. 10.793/2003 (BRASIL, 2003). Porém, há também uma forma equivocada de gerir a organização pedagógica das aulas e turmas de ensino que não permite ao professor de EF trabalhar com turmas do mesmo ano de ensino ou modalidade de EM. A distribuição de turmas ocorre motivada pela adequação de horário, sem que sejam priorizados a experiência e o trabalho pedagógico do professor com determinadas turmas de ensino e plataforma curricular. Um mesmo professor leciona para turmas do primeiro ao terceiro ano, do EM Regular ou Técnico, sem que se exija uma atuação mais articulada com a proposta pedagógica da escola em relação à modalidade de EM.

A análise do planejamento anual de EF sugere não ter sido proposto e organizado a partir de uma construção compartilhada com os jovens alunos, ou se referindo ao Projeto Pedagógico da escola, pois há uma evidente incoerência pedagógica e curricular entre o que se determina como Competências e habilidades da área de linguagem para o EM e a organização dos conteúdos por bimestres e turmas do EM, com a eleição do esporte como a prática corporal principal, senão a única a ser ensinada nas aulas, conforme descrito a seguir: 
Quadro 1 - Conteúdos bimestrais de EF para o EM

\begin{tabular}{|c|c|c|c|}
\hline & Primeiros anos do EM & Segundo anos do EM & Terceiros anos do EM \\
\hline 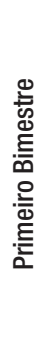 & $\begin{array}{l}\text { Revisão das regras do basquetebol } \\
\text { Técnicas e táticas do basquetebol } \\
\text { Fundamentos do basquetebol } \\
\text { Aquecimento } \\
\text { Alongamento } \\
\text { Sedentarismo } \\
\text { Dama; Xadrez; Bozó; Dominó; Tênis } \\
\text { de mesa } \\
\text { Voleibol recreativo } \\
\text { Atividades lúdicas }\end{array}$ & $\begin{array}{l}\text { Revisão das regras do basquetebol } \\
\text { Técnicas e táticas do basquetebol } \\
\text { Fundamentos do basquetebol } \\
\text { Importância do alongamento } \\
\text { Benefícios da atividade física } \\
\text { Dama; Xadrez; Bozó; Dominó; Tênis } \\
\text { de mesa } \\
\text { Voleibol recreativo } \\
\text { Atividades lúdicas }\end{array}$ & $\begin{array}{l}\text { Revisão das regras do basquetebol } \\
\text { Técnicas e táticas do basquetebol } \\
\text { Fundamentos do basquetebol } \\
\text { Importância do alongamento } \\
\text { Qualidade de vida } \\
\text { Teste: qualidade de vida } \\
\text { Dama; Xadrez; Bozó; Dominó; Tênis de mesa } \\
\text { Voleibol recreativo } \\
\text { Atividades lúdicas }\end{array}$ \\
\hline 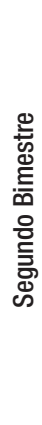 & $\begin{array}{l}\text { Revisão das regras do handebol } \\
\text { Técnicas e táticas do handebol } \\
\text { Fundamentos do handebol } \\
\text { Atividade física regular aliada a boa } \\
\text { alimentação } \\
\text { Pirâmide da atividade física } \\
\text { Alimentação saudável } \\
\text { Pirâmide da alimentação } \\
\text { Dama; Xadrez; Bozó; Dominó; Tênis } \\
\text { de mesa } \\
\text { Voleibol recreativo } \\
\text { Atividades lúdicas }\end{array}$ & $\begin{array}{l}\text { Revisão das regras do handebol } \\
\text { Técnicas e táticas do handebol } \\
\text { Fundamentos do handebol } \\
\text { Tipos de calorias } \\
\text { Vitaminas } \\
\text { Minerais } \\
\text { Dama; Xadrez; Bozó; Dominó; Tênis } \\
\text { de mesa } \\
\text { Voleibol recreativo } \\
\text { Atividades lúdicas }\end{array}$ & $\begin{array}{l}\text { Revisão das regras do handebol } \\
\text { Técnicas e táticas do handebol } \\
\text { Fundamentos do handebol } \\
\text { Doenças associadas a falta de atividade física } \\
\text { Dama; Xadrez; Bozó; Dominó; Tênis de mesa } \\
\text { Voleibol recreativo } \\
\text { Atividades lúdicas }\end{array}$ \\
\hline 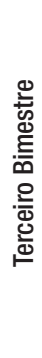 & $\begin{array}{l}\text { Revisão das regras do voleibol } \\
\text { Técnicas e táticas do voleibol } \\
\text { Fundamentos do voleibol } \\
\text { Drogas e seus efeitos } \\
\text { Alcoolismo } \\
\text { Tabagismo } \\
\text { Dama; Xadrez; Bozó; Dominó; Tênis } \\
\text { de mesa } \\
\text { Voleibol recreativo } \\
\text { Atividades lúdicas }\end{array}$ & $\begin{array}{l}\text { Revisão das regras do voleibol } \\
\text { Técnicas e táticas do voleibol } \\
\text { Fundamentos do voleibol } \\
\text { Obesidade } \\
\text { IMC } \\
\text { Dama; Xadrez; Bozó; Dominó; Tênis } \\
\text { de mesa } \\
\text { Voleibol recreativo } \\
\text { Atividades lúdicas }\end{array}$ & $\begin{array}{l}\text { Revisão das regras do voleibol } \\
\text { Técnicas e táticas do voleibol } \\
\text { Fundamentos do voleibol } \\
\text { Exercícios aeróbicos e anaeróbicos } \\
\text { Dama; Xadrez; Bozó; Dominó; Tênis de mesa } \\
\text { Voleibol recreativo } \\
\text { Atividades lúdicas }\end{array}$ \\
\hline 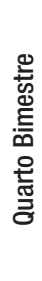 & $\begin{array}{l}\text { Revisão das regras do futsal } \\
\text { Técnicas e táticas do futsal } \\
\text { Fundamentos do futsal } \\
\text { DST } \\
\text { Dama; Xadrez; Bozó; Dominó; Tênis } \\
\text { de mesa } \\
\text { Voleibol recreativo } \\
\text { Atividades lúdicas }\end{array}$ & $\begin{array}{l}\text { Revisão das regras do futsal } \\
\text { Técnicas e táticas do futsal } \\
\text { Fundamentos do futsal } \\
\text { Problemas posturais } \\
\text { Dama; Xadrez; Bozó; Dominó; Tênis } \\
\text { de mesa } \\
\text { Voleibol recreativo } \\
\text { Atividades lúdicas }\end{array}$ & $\begin{array}{l}\text { Revisão das regras do futsal } \\
\text { Técnicas e táticas do futsal } \\
\text { Fundamentos do futsal } \\
\text { Esteroides anabolizantes } \\
\text { Problemas posturais } \\
\text { Dama; Xadrez; Bozó; Dominó; Tênis de mesa } \\
\text { Voleibol recreativo } \\
\text { Atividades lúdicas }\end{array}$ \\
\hline
\end{tabular}

Fonte: Reprodução do Planejamento Anual de EF do professor. 
Quadro 2 - Plano de Ensino de EF - Ensino Fundamental e Médio

Objetivo Geral da EF: Desenvolver o educando de maneira global em seus aspectos sócio afetivo, cognitivo e motor.

\begin{tabular}{|c|c|c|c|}
\hline Competências & & Habilidades & Metodologia \\
\hline \multirow{3}{*}{$\begin{array}{l}\text { Compreender o funcionamento do } \\
\text { organismo humano, de forma a reconhecer } \\
\text { e modificar as atividades corporais, } \\
\text { valorizando-as como recurso para melhoria } \\
\text { de suas aptidões físicas. } \\
\text { Desenvolver as noções conceituais de } \\
\text { esforço, intensidade e frequência aplicando- } \\
\text { as em suas práticas corporais. } \\
\text { Refletir sobre as informações específicas de } \\
\text { cultura corporal, sendo capaz de discerni- } \\
\text { las e reinterpretá-las em bases científicas, } \\
\text { adotando uma postura autônoma na seleção } \\
\text { de atividades e procedimentos para a } \\
\text { manutenção ou aquisição de saúde. } \\
\text { Assumir uma postura ativa, na prática } \\
\text { das atividades físicas e consciente da } \\
\text { importância delas na vida do cidadão. }\end{array}$} & 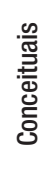 & $\begin{array}{l}\text { Conhecer os benefícios das atividades } \\
\text { físicas; } \\
\text { Identificar diferentes tipos de jogos, } \\
\text { esportes e danças; } \\
\text { Reconhecer e valorizar as regras. }\end{array}$ & $\begin{array}{l}\text { Aulas práticas e expositivas; } \\
\text { Pesquisas e trabalhos em grupos; } \\
\text { Cartazes, filmes, seminários e } \\
\text { vídeos. }\end{array}$ \\
\hline & 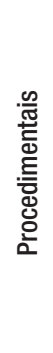 & $\begin{array}{l}\text { Analisar e estudar as regras; } \\
\text { Praticar esportes, dança, ginástica, lutas } \\
\text { e jogos; } \\
\text { Participar de jogos cooperativos e das } \\
\text { competições organizadas pela escola. } \\
\text { Participar de atividades em grandes } \\
\text { e pequenos grupos, compreendendo } \\
\text { as diferenças individuais e procurando } \\
\text { colaborar para que o grupo possa atingir os } \\
\text { objetivos a que se propôs. }\end{array}$ & $\begin{array}{l}\text { Através de jogos, lutas, danças, } \\
\text { atividades rítmicas, ginástica; } \\
\text { Projetos: Olimpíadas, folclore, } \\
\text { gincanas, mostra de ciências, } \\
\text { outros. }\end{array}$ \\
\hline & 管 & $\begin{array}{l}\text { Valorizar as diferenças físicas, culturais e } \\
\text { sociais; } \\
\text { Mudança de comportamento no ambiente } \\
\text { escolar de modo a tornar-se mais sociável } \\
\text { e humano; } \\
\text { Interessar-se pelo surgimento das múltiplas } \\
\text { variações da atividade física, enquanto } \\
\text { objeto de pesquisa, área de grande } \\
\text { interesse social e mercado de trabalho } \\
\text { promissor; } \\
\text { Demonstrar autonomia na elaboração } \\
\text { de atividades corporais, assim como a } \\
\text { capacidade de discutir e modificar regras. }\end{array}$ & $\begin{array}{l}\text { Observação do comportamento } \\
\text { nas aulas práticas. }\end{array}$ \\
\hline
\end{tabular}

Avaliação da Aprendizagem Conceitual: Trabalho; seminários; prova escrita, relatórios individuais.

Avaliação da Aprendizagem Procedimental: Participação nas diferentes atividades promovidas pela escola.

Avaliação da Aprendizagem: Observação e autoavaliação.

Fonte: Reprodução do Planejamento Anual de EF do professor.

0 plano de ensino anual da disciplina de EF é único para o ensino fundamental e médio. A especificidade de cada nível de ensino e demandas formativas dos jovens alunos não são consideradas. Além disso, não faz nenhuma menção às particularidades do ensino da EF para o ensino médio integrado à educação profissional (Curso técnico de administração e informática). Esses aspectos são observados pelos jovens alunos ao serem questionados sobre as contribuições da EF no curso de ensino médio técnico:

Diretamente acho que não tem. (0 - Primeiro K ADM - M - 15 anos).

Acho que não tem nenhuma relação. Pra gente se exercitar. (I - Primeiro I INF - M - 15 anos). 
0 professor tenta colocar a disciplina no nosso curso, pra fica mais fácil de entender. (Pensativa). Ai, não sei, ah! (E - Primeiro J INF - F -15 anos).

Os apontamentos dos que cursam os cursos médios técnicos em Administração e Informática indicam a importância da EF (re)avaliar o seu papel pedagógico em sintonia com as especificidades das propostas de ensino e aprendizagem das formações médias técnicas, quando compõem o seu itinerário formativo. Isso enseja refletir os sentidos de suas práticas de ensino, a fim de que possa se lançar em direção às diferentes estratégias metodológicas, que possam alinhar as contribuições da EF ao ensino médio técnico. Há que se encontrar pontos de equilíbrios entre o que é geral (rol de conhecimentos indispensáveis da disciplina) e o que é particular (conjunto de conhecimentos e temáticas da EF que, potencialmente, contribuem para formação do aluno em cursos técnicos).

Para Silva, Silva e Molina Neto (2016, p. 333-334), as reflexões curriculares e pedagógicas a respeito do papel e o ensino da EF em cursos de ensino médio técnicos direcionam-se para:

[...] além do mero "exercitar-se", ou de fornecer "dicas" técnicas sobre como manter o corpo saudável, ou produtivo, ao gosto do mercado de trabalho, como se fôssemos exclusivamente profissionais da saúde e não docentes de EF. Um modo concreto de realizar esse intento é proporcionar aos estudantes, nas escolas, o acesso a conhecimentos que os auxiliem a compreender os determinantes objetivos envolvidos na disputa por modelos de práticas e de condutas corporais, por exemplo, aqueles que procuram reduzir o conceito de qualidade de vida às características subjetivas do "estilo de vida".

Sem a pretensão de fazer recomendações que parecem não respeitar aqueles e aquelas que estão no chão da escola, e que agonizam frente à precarização do trabalho docente nas escolas, ou de ordem abstrata e genérica, baseada em juízo de valor, propomos o desafio de se fazer a leitura do conjunto de motivos, interesses e imposições que levam os jovens alunos a decidirem pela formação média técnica, para com eles e em função deles promovermos propostas de ensino de EF contextualizadas, que lhes permitam enxergar as contribuições das práticas corporais em sua formação humana. Buscamos, assim, dar concretude às ações pedagógicas significativas e um lugar de merecimento - e não meramente obrigatório - para EF no currículo escolar da formação média técnica.

\section{A aula prática de EF no EM}

Como a aula de EF acontece no horário regular de ensino, os jovens alunos frequentam-na com o uniforme (camiseta) e demais vestimentas e acessórios que costumeiramente adornam seu corpo para irem à escola. Há uma polissemia de estilos juvenis presentes na aula, conforme extrato de observação:

Não é cobrado dos "jovens alunos" que venham com roupa esportiva para as aulas de EF. Os "jovens alunos” jogam com a roupa que vieram para escola - uniforme obrigatório. Há uma diversidade de vestimentas presentes na aula, pois os "jovens alunos" usam calça jeans, saia, calça legue, short de tectel (estampado ou praiano), tênis, coturnos, sapatilhas (floridas, 
estampadas, com brilho), rasteirinhas, chinelos, agasalhos amarrados na cintura, cabelos soltos ou presos, celulares nos bolsos e fones nos ouvidos, pulseiras coloridas, entre muitos outros adereços próprios da moda e estilo juvenil. Alguns "jovens alunos" preferem trocar o uniforme da escola por uma roupa mais leve. (Extrato de observação das aulas de EF da turma de segundo ano K, do ensino médio técnico em administração, em 27 de abril de 2016).

Exemplifica-se com o registro de observações a organização pedagógica da aula de EF, recorrente no segundo e terceiro bimestre letivo de 2016, independentemente, da turma ou conteúdo de ensino:

Encontro com o professor que estava em outra turma de EM, em sala de aula com Jogos de Xadrez e Dama. A próxima aula é na quadra de Vôlei descoberta da escola. 0 professor reúne os "jovens alunos" que se dividem em duas equipes e começam um jogo misto de voleibol. Eles parecem gostar do Vôlei. Não há aquecimento ou qualquer forma de alongamento. Nada parece atrapalhar o jogo entre amigos. Os alunos gritam, se alternam, saem e voltam e se motivam para continuar o jogo até o final da aula. (Extrato de observação das aulas de EF, da turma de segundo ano K, do ensino médio técnico em administração, em 20 de abril de 2016).

Com base em Caparroz e Bracht (2007, p. 29), rejeita-se a “[...] pretensão 'pífia' e 'falaciosa' de que uma mesma aula pode ser aplicada a várias e diferentes turmas”, e que assim desvaloriza a compreensão de que a "[...] a condição humana de nossos alunos impõe um caráter irrestritamente singular às nossas aulas”. 0 professor de EF assumiu uma representação de que está ali para assegurar que o jogo aconteça livre de agressões físicas e verbais. 0 seu corpo-mensageiro (BAUMAN, 2011) indica que não haverá nenhuma outra proposição pedagógica na aula que não seja o jogo de amigos.

As entrevistas com os jovens alunos esclareceram como registram a rotina das aulas de EF no EM:

Nois chega, troca de roupa, se prepara para EF. E aí, espera normalmente o professor na quadra para decidir o que a gente vai fazer. Hoje ele resolveu dá o vôlei, mas tem vez de quando que ele vem aqui dá a bola de Handebol. (0 - Primeiro K - M - 15 anos).

Quando é Handebol, a gente alonga tudo aqui, aprende passos novos, até o futsal. Vôlei não, ele ensino a gente bastante no ano passado. A gente chega e joga. A gente já sabe e o Handebol, não. (T - Primeiro K - F - 15 anos).

É, tem aula prática e teórica. Prática ou é Vôlei ou futsal. Handebol não teve nenhuma aula prática ainda, só teórica. (A - Terceiro F - F - 16 anos).

0 jogo de vôlei é monopolizado por quem sabe jogar. Não importa a regra oficial do esporte. A aula acontece. Os jovens alunos jogam vôlei, sem qualquer interferência pedagógica ou coercitiva do professor de EF. Eles parecem identificar-se com o jogo de vôlei, que se apresenta como uma modalidade esportiva aparentemente inclusiva, ao permitir que meninos e meninas joguem juntos. Por outro lado, essa dinâmica dos jovens alunos em se 
auto-organizarem para o que será jogado e por quem será jogado é, por vezes, perversa. 0 olhar mais atento à forma e isolamento de grupos de jovens alunos indica a presença de grupos juvenis de estabelecidos e outsiders (ELIAS; SCOTSON, 2000), que são excluídos e ao mesmo tempo, como mecanismo de defesa, parecem representar uma indiferença sobre o processo de exclusão, por lhe restarem apenas o terceiro tempo de jogo, se houver.

0 professor de EF confunde-se ao querer justificar que por detrás da simples aparência de um jogo descompromissado de vôlei entre colegas de sala de aula há uma intenção pedagógica de organização da EF; ou ao explicar que, como o Complexo Esportivo é utilizado para as aulas de EF, por diferentes professores, no mesmo horário, se organizaram para oferecer a vivência do esporte aos jovens alunos, de forma que uma turma fica na quadra descoberta de vôlei (fora) e a outra, no ginásio de esporte com o futsal (dentro). Os jovens alunos podem optar por praticar uma modalidade ou outra.

Essa dimensão do simples assim revela que muitas das nossas ações são habituais e rotineiras. Para Bauman (2011), porquanto as ações permanecem habituais, raramente nos detemos para questionar os valores a que elas servem. A prática pedagógica rotineiramente observada faz ponderar que não se tem priorizado na proposição pedagógica das aulas a "[...] participação ativa e crítica dos alunos nas diferentes tarefas que se desenvolvem na aula e que constituem o modo de viver da comunidade democrática de aprendizagem" (GOMÉZ, 1998, p. 26). Essa situação faz recomendar a organização dos tempos e espaços escolares de uma forma flexível e a construção de propostas pedagógicas que dialoguem com os jovens alunos, de modo a que não se limite a preencher o tempo na escola.

Essas experiências pedagógicas registradas nas aulas de EF no EM parecem desconsiderar que "[...] a escola é uma instituição social, na qual, transita um contingente significativo da juventude brasileira” (DAYRELL; GOMES; LEÃO, 2010, p. 250), e que assim nos desafia enquanto educadores:

[...] a construir outro tipo de organização do trabalho pedagógico e a rever suas instâncias de participação, considerando não somente o mundo adulto, mas, também, as temporalidades humanas com as quais convive. (DAYRELL; GOMES; LEÃO, 2010, p. 251).

0 professor de EF defende que nas aulas práticas, os jovens alunos de diferentes turmas podem se misturar para jogar, para que: "Não seja uma coisa excludente”. Os jovens alunos escolhem o vôlei ou o futsal, ou podem, ainda, jogar nas quadras descobertas de minibasquete. Diferentemente dessas alegações, os jovens alunos avaliaram que esse modus operandi da EF não atende suas expectativas e em nada contribui com as demandas de estudo e preparação para ingresso no Ensino Superior, que os aflige tanto nesse momento da juventude, principalmente, aqueles que estão no último ano do EM:

Acho que não serve, porque a maioria tá aqui para fazer um curso, sabe. Ou então, vestibular, ENEM. A EF não é muito ENEM. Ainda mais o modo que ele dá aula, não é não. Esse modo faz a diferença, claro. ( $\mathrm{M}$ - Terceiro F - M - 17 anos).

$\mathrm{Eu}$ acho que é importante atividade física. Mais aqui, é uma perca de tempo. A gente tem muito mais conteúdo para você aprender do que a EF. Se a gente estudasse mesmo algum tipo de doença que causasse o sedentarismo. Mas aqui!!!. (A - Terceiro F - F - 16 anos). 
Os jovens alunos quando indagados acerca das contribuições da EF no EM disseram que:

Acho que sim, contribui. (0 - Primeiro $\mathrm{K}-\mathrm{M}-15$ anos).

Ah! Sim, ensina um esporte. (T - Primeiro K - F - 15 anos).

Sim... não sei. (I - Primeiro I INF - M - 15 anos).

Prá joga... joga. (E - Primeiro J INF - F - 15 anos).

Ah! 0 esporte. No primeiro bimestre foi o Vôlei. ( $M$ - Terceiro $F-M-17$ anos).

Os jovens alunos descreveram nas entrevistas, ao dizer sobre como se configura o cotidiano das aulas de EF no EM, que essas não diferem muito do que lhes foi oferecido no Ensino Fundamental, em outras escolas ou mesmo na escola investigada:

Quadro 3 - Memórias das experiências dos jovens alunos com a EF na vida escolar

\begin{tabular}{|c|c|c|c|c|}
\hline Codinomes & Respostas & Conteúdo & Método & Concepções \\
\hline $\begin{array}{l}0-\text { Primeiro } K- \\
M-15 \text { anos }\end{array}$ & $\begin{array}{l}\text { Participava. Costumava ser só futebol. A } \\
\text { professora chega, dava a bola para nóis e só. }\end{array}$ & $\begin{array}{l}\text { Esporte - prática de } \\
\text { futebol }\end{array}$ & "Rola bola" & Esporte \\
\hline $\begin{array}{l}\mathrm{T}-\text { Primeiro } \mathrm{K}-\mathrm{F} \\
-15 \text { anos }\end{array}$ & $\begin{array}{l}\text { Não, não muito, porque era de manhã, não } \\
\text { dava para eu ir, eu tinha coisa para fazer em } \\
\text { casa. Eu fui umas...duas vezes. A gente jogava } \\
\text { vôlei, handebol e futsal, na maioria da vezes. } \\
\text { Fora isso... }\end{array}$ & $\begin{array}{l}\text { Esporte - Vôlei, Handebol } \\
\text { e Futsal }\end{array}$ & Jogar os esportes & Esporte \\
\hline $\begin{array}{l}\text { I - Primeiro I INF- } \\
\mathrm{M}-15 \text { anos }\end{array}$ & $\begin{array}{l}\text { Sim, não era muito bom. Porque no meu time } \\
\text { só tinha garoto pequeno, era contra, tudo junto. } \\
\text { Primeiro, Segundo, Terceiro, era difííl jogar } \\
\underline{\text { bola assim. Era baixinho contra os caras altos. }} \\
\underline{\text { A EF é tudo misturado, à tarde, fora do horário. }}\end{array}$ & Esporte-Futebol & $\begin{array}{l}\text { Diversas turmas } \\
\text { misturadas de Ensino } \\
\text { Fundamental e Médio } \\
\text { sem preocupação com } \\
\text { a diferenciação de } \\
\text { conteúdos e práticas }\end{array}$ & Esporte \\
\hline $\begin{array}{l}\text { E - Primeiro J } \\
\text { INF- F-15 anos }\end{array}$ & $\begin{array}{l}\text { Sim, sempre. Ah! Era legal. Sempre joguei bola. Eu } \\
\text { gosto de jogar bola. Eu gosto mais de jogar bola. }\end{array}$ & Esporte - Futebol & Jogar o futebol & Esporte \\
\hline $\begin{array}{l}\mathrm{M}-\text { Terceiro } \mathrm{F}-\mathrm{M} \\
-17 \text { anos }\end{array}$ & $\begin{array}{l}\text { Sim, futebol, futsal. As vezes tinha vôlei, } \\
\text { basquete. Mas a maioria era futsal. }\end{array}$ & $\begin{array}{l}\text { Esporte - Futebol com } \\
\text { algumas vivências de Vôlei } \\
\text { e Basquete }\end{array}$ & Jogar os esportes & Esporte \\
\hline $\begin{array}{l}\text { A - Terceiro F- F- } \\
16 \text { anos }\end{array}$ & $\begin{array}{l}\text { Mais ou menos. } 0 \text { professor fazia tipo um } \\
\text { treinamento antes e deixa a gente praticar algum } \\
\text { esporte. Cada bimestre era um esporte. E os } \\
\text { professores, pegavam algum tema que podia cair } \\
\text { no ENEM prá trabalhar. Vamos supor, tipo, que } \\
\text { podia cair "Atividade Física". }\end{array}$ & $\begin{array}{l}\text { Jogar esportes - com } \\
\text { rodízio de modalidades } \\
\text { esportivas por bimestres e } \\
\text { a discussão de temáticas } \\
\text { relacionadas à EF e } 0 \\
\text { ENEM }\end{array}$ & $\begin{array}{l}\text { Prioritariamente jogar } \\
\text { os esportes }\end{array}$ & $\begin{array}{l}\text { Esporte e } \\
\text { Atividade } \\
\text { Física }\end{array}$ \\
\hline
\end{tabular}

Fonte: Construção dos pesquisadores. 
Foi observado que os jovens alunos chegam, vão jogar e há aqueles que ficam de fora. É interessante esse modus operandi apenas do ponto de vista que permite o encontro e a interação social entre alunos da mesma turma ou de diferentes turmas, heterossexuais ou homossexuais, baixos ou magros, brancos ou negros. Entretanto, não há uma ação pedagógica direta nas aulas para que os jovens alunos aprofundem seus conhecimentos sobre a cultura corporal de movimento, em uma dimensão conceitual, procedimental ou atitudinal, como é proposto no Planejamento Anual de Ensino de EF.

Durante a ocorrência do Conselho de Classe, os jovens alunos representantes do Grêmio Estudantil organizam-se para realização de interclasse esportivo entre os jovens alunos do EM, sem que houvesse ou necessitasse de interferência ou acompanhamento pedagógico do professor de EF, pois se auto-organizaram, inclusive, para arbitragem dos jogos. Esse é um exemplo de ação protagonista do jovem aluno que parece não ser validada pela EF que se oferta nessa escola.

Os diálogos captados revelaram-nos que os jovens alunos esperam, inclusive, a aprender a jogar. Eles parecem clamar por um aprender, que lhes permita um contraponto com relação ao que sabem e julgam saber sobre as práticas corporais registradas em suas memórias, referente ao seu patrimônio corporal. Outras experiências corporais, que não sejam tão só as mesmas vivenciadas pelas aulas de EF do Ensino Fundamental, ou em outro nível de complexidade que respeitem a sua condição juvenil. Ou seja, aulas de EF no EM que não resumam suas diferenças às aulas no Ensino Fundamental apenas em função da qualidade do espaço físico, conforme foi apontado: "A diferença é que aqui a quadra é bem arrumada, não pega sol, é quadra fechada, não é quente. E aqui a gente pode jogar descalço que não machuca o pé” (E - Primeiro J INF - F - 15 anos).

Para tanto, é necessário saber ver e ouvir os jovens alunos e reconhecer que:

Os jovens precisam de "tempos" e "espaços" não apenas para receber projetos pré-concebidos por lógicas adultas; eles e elas querem dizer o que precisam e sinalizar para o que podem fazer individual e coletivamente. (CARRANO, 2012, p. 90).

Ou seja, trata-se de reconhecer o jovem aluno como "[...] interlocutor válido, capaz de emitir opiniões e interferir nas propostas que lhe dizem respeito, estimulando a sua participação e o seu protagonismo" (DAYRELL, 2009, p. 16).

A aula prática de EF no EM configurou-se em um tempo e espaço de recreação. Ao organizar esse modelo de aula tem-se a concepção de se possibilitar aos jovens alunos vivenciarem o esporte de seu maior interesse. Será mesmo? Ou, talvez, essa escolha seja motivada mais por uma comodidade; mais por inibição ou receio em se expor a jogar outra prática que não se conheça; mais em função dessa organização pedagógica recorrente.

A aparente frivolidade recreativa do jogo entre amigos de classe, por si só inclusiva, esconde o "pseudoprojeto emancipatório de EF para o EM", que continua a operar no cotidiano escolar e na EF que se faz para as juventudes na escola brasileira, pois não reconhece a condição juvenil dos alunos, na ambiência da sua época. Dito de outra forma, ignora a compreensão das peculiaridades da escola jovem e o jovem aluno como sujeito do processo educativo (BRASIL, 2012).

Dificulta-se o trabalho pedagógico do professor de EF em oferecer uma proposta curricular e pedagógica, com uma sistematização de saberes sobre as práticas corporais, 
de forma contínua, com nível de complexidade crescente, pois a aula prática de EF se faz dependente desse acordo de cavalheiros, de forma que as vivências e aprendizagens sejam limitadas apenas ao esporte.

A aula de EF e o recreio confundem-se. Muitas vezes, foi presenciado que o término da aula não significava o término do jogo que se prolongava pelo recreio, assim como o contrário também é verdadeiro.

É notório como os jovens alunos identificam-se com as práticas corporais esportivas, pois as quadras do complexo esportivo estavam lotadas o tempo todo. Parecem ser o point da escola, onde os jovens alunos encontram-se, procuram sempre estar juntos para jogar, para conversar, para namorar, para fotografar a si e aos outros, para viverem sua condição juvenil.

As Orientações Curriculares para o Ensino Médio (BRASIL, 2006, p. 220) avaliam que são múltiplas:

As formas como cada um dos jovens enxerga a escola e suas possibilidades de exercícios de práticas corporais são várias: como forma de ascensão social; como espaço de encontro, local de expressão e troca de afetos; como lugar de tédio e de rotinas sem sentido, entre outros. Cada uma dessas formas precisa ser pensada pela escola ao construir sua relação com os alunos. 0 projeto maior de formação da escola precisa dialogar com os vários projetos dos jovens que a compõem.

$\mathrm{Na}$ aula de EF no EM, avalia-se como sintomático o vazio e desafio pedagógico a serem enfrentados pela disciplina nesse nível de ensino, principalmente, o fato que de há ainda uma ideia e prática pedagógica reinantes sob a perspectiva da recreação, de participação livre e descompromissada, que ainda são presentes no cotidiano da cultura escolar das aulas de EF no EM. Trata-se de uma aula que padece com e da falta da interferência pedagógica do professor, de forma que a participação coletiva de todos depende ou fica à mercê do grupo, que impõe um tipo de prática no interior da escola, tal como vivenciam fora da escola, sem qualquer avaliação pedagógica sobre os sentidos e as formas de exclusão que, amiúde, ajudam a reproduzir.

Os jovens alunos chegam para jogar, jogam e se vão. Essa realidade desafiou-nos a investigar como veem as contribuições da presença da EF nesse nível de escolarização:

Quadro 4 - Representações e finalidades da EF no EM

\begin{tabular}{|l|l|l|}
\hline \multicolumn{1}{|c|}{ Qual é o papel da EF no EM? Para que serve? Para que contribui? } & \multicolumn{1}{|c|}{ Cospostas } \\
\hline Codinomes & \multicolumn{1}{|c|}{ Rentribuições } \\
\hline - Primeiro K-M - 15 anos & $\begin{array}{l}\text { No EM... colabora também, pois tem muitos alunos no EM que continua } \\
\text { sedentário, que fica só no celular, com a nova geração, a geração "Z" que } \\
\text { chegou. Fica todo mundo na tecnologia e esquece a atividade física. No EM } \\
\text { já ajuda bastante. }\end{array}$ & $\begin{array}{l}\text { Combate ao sedentarismo } \\
\text { físico motivado pelas TIC's }\end{array}$ \\
\hline T-Primeiro K-F-15 anos & $\begin{array}{l}\text { Mantém o corpo saudável e bem em forma, também. Mostra para as } \\
\text { pessoas que tem que fazer exercício físico, tipo sentado, não ficarem assim } \\
\text { com a vida meio ruim. }\end{array}$ & $\begin{array}{l}\text { Incentivar a prática de } \\
\text { exercício físico }\end{array}$ \\
\hline I- Primeiro I INF-M - 15 anos & $\underline{\text { Acho que sim. Me ajuda, a não ficar parado. }}$ & Combate à imobilidade física \\
\hline
\end{tabular}


Fonte: Construção dos pesquisadores.

Os jovens alunos ao discorrem sobre o papel pedagógico da EF no EM o fazem na direção de uma compreensão da visão social e educativa da disciplina diretamente relacionada à "[...] disciplinarização e o condicionamento do corpo, com pressupostos teóricos e justificativas de ações no campo biofisiológico” (BRASIL, 2006, p. 213), o que pareceu ser produto do modo como lhes foi ensinado a sua serventia. Sem que as práticas e discussões nas aulas dessa disciplina lhes alertassem para as pluralidades de culturas e implicadores sociais e econômicos sobre o acesso à saúde e ao movimento corporal, a partir da sua realidade social e da vida em comunidade.

Aos jovens alunos, o discurso da saúde que lhes ocorre pareceu referendado no sentido do fazer exercício. A preocupação, portanto, é com a adoção do hábito da prática regular de exercício físico de fins higienistas. A saúde é unicamente compreendida como consequência direta da prática regular de atividades físicas, em detrimento de uma discussão dos aspectos sociais e econômicos que envolvem a vida humana, principalmente, na fase adulta.

Não se quer com isso desvalorizar a incorporação dos exercícios físicos à rotina da vida, mas propor que a EF possibilite discussões acerca dos comportamentos com e para a saúde mais críticas sobre a realidade social das comunidades. Portanto, que não se limite a propagar a relação saúde e exercício físico sem discutir as condições sociais de vida dos homens. Isto é, possibilitar ao jovem aluno a emancipação crítica para vida individual e coletiva.

As aulas de EF no EM encerram-se com o soar do sino, sem qualquer recomendação, tarefa para casa, anúncio do que vem na próxima aula, sem qualquer reflexão final. Simplesmente acabam.

\section{A aula teórica de EF no EM}

A organização pedagógica da aula de EF para o EM lida com a alternância de aula teórica em sala de aula (espaço fechado) e aula prática (espaço aberto no complexo esportivo). 0 extrato de observação ilustra uma aula teórica:

0 professor explica que em função das paralisações, Conselho de Classe, entre outros, os conteúdos estão atrasados. Foi oferecida anteriormente uma aula prática de Handebol, e agora, em sala de aula, os alunos devem ler a apostila, que é o material didático escrito, e responder ao questionário que vale 3,0 pontos. 0 professor diz aos alunos: - Vou vistar! Quem não fizer, não atrapalha os demais! Neste dia, houve um desencontro entre os alunos, de forma, que alguns foram ao Complexo Esportivo e os demais estavam em sala aguardando o professor para início da aula. 0 professor explica: - Todos sabiam que a aula era aqui! A anterior foi prática, essa é teoria e a próxima é na sala de vídeo. (Extrato de observação das aulas de EF da turma de Terceiro Ano F, em 15 de junho de 2015).

Surpreende o fato de que mesmo sendo o início da aula, o professor não leu, não comentou, não explicou, ao menos ressaltou o objetivo e sentido pedagógico da aula 
e da leitura do material escrito acerca das regras do handebol e das doenças crônicas e degenerativas ligadas ao sedentarismo. 0 professor espera sentado em sua mesa, localizada do lado direito da sala de aula, próxima às janelas, que os alunos iniciem os exercícios da apostila. Essa imagem fez-nos questionar: Qual o sentido do estudo teórico das regras de handebol para jovens alunos do Terceiro Ano do EM que estão na iminência do vestibular e do ENEM ou da entrada no mercado de trabalho? Será que esses jovens alunos nunca estudaram as regras de Handebol em anos anteriores nas aulas de EF? Qual a importância e relevância do estudo das regras de handebol com jovens alunos do Terceiro Ano do EM?

É interessante registrar que há uma intenção pedagógica do professor ao alternar a aula prática no complexo esportivo, aula teórica na sala de aula da turma e uma aula com recursos visuais, por assim acreditar abarcar os conteúdos de forma mais abrangente e significativa para os jovens alunos. Outro importante fato é a organização do material didático de forma escrita e sistematizada, mas que não garantiu por si só maior sucesso pedagógico.

A princípio, tem-se uma imagem desanimadora ou desencantada do fazer pedagógico do professor de EF e do como os jovens alunos atribuem sentidos a essa aula teórica, que é uma única aula semanal por turma, fechada no espaço da sala de aula, conforme extrato de entrevista:

Eu odeio EF, porque eu acho que não vai acrescentar muita coisa. Quando sim, trabalha com o ENEM. É que a gente só joga algum esporte. No momento, a gente, tá estudando handebol! Handebol num vai cai. (A - Terceiro F - F - 16 anos).

Na teórica, aprende as regras de alguns jogos. Os troféus que a nossa seleção já ganhou. Tipo isso. Futebol, Vôlei, Handebol, às vezes, Basquete. É isso que tem. (I - Primeiro I INF - M - 15 anos).

Eu gosto de mais prática. Teórica é mais chato, não. Teórica, não. (M - Terceiro F - M - 17 anos).

Há uma desregulação das relações e intenções pedagógicas. 0 contrato do trabalho entre professor e aluno supõe um quadro normativo de obrigações escolares, que tem uma interessante proposição pedagógica, mas que no tempo e espaço das aulas são pautadas no fazer pelo fazer, no cumprir controladamente o sistema apostilado de conteúdo, sem se preocupar com a apropriação crítica e reflexiva do conhecimento. Há que se refletir, ainda que:

O SENTIDO DA ESCOLA para os estudantes está bastante vinculado à integração escolar do aluno e à sua identificação com o professor. 0 interesse pela disciplina está diretamente associado à ATITUDE DO DOCENTE: ao jeito de ensinar, sua paciência com os alunos e capacidade de estimulá-los. (KRAWCZKY, 2014, p. 88).

Agrava a situação o quadro disciplinar da turma, com o reincidente descumprimento da função aluno, que parece ser banalizada ou invisibilizada pelo professor de EF. De forma que alguns alunos não cooperam com a própria aprendizagem, por outro lado, não são chamados a cooperar. 0 professor de EF não se incomoda com o comportamento 
desajustado do aluno, de forma que a lógica docente não se impõe sobre a lógica discente. É notória sua apatia política e pedagógica, seja diante do comportamento dos alunos ou na sua falta de colaboração junto aos demais jovens alunos que se esforçam - à sua maneira - para cumprir, apenas cumprir, os exercícios a serem avaliados.

Dubet, em entrevista a Peralva e Sposito (1997, p. 228), avalia a sua experiência como professor de História e Geografia, por um ano, em um colégio da periferia de Bordeaux, França, e comenta que a escola não deve se transformar em um clube de vida juvenil, mas:

Até um certo ponto, é preciso que o colégio aceite que haja uma vida adolescente na escola e que não a considere como desvio. É preciso dar um quadro a esta vida adolescente, é preciso que os alunos façam outras coisas que não seja assistir às aulas no colégio, mas eles devem fazê-lo num quadro normativo, com regras que os eduquem [...].

Dubet enfatiza que é preciso encontrar “[...] modos de organização que farão com que o trabalho seja coordenado" (PERALVA; SPOSITO, 1997, p. 229), que não se caracterizem pela pedagogia da acumulação. Parece que produzir um material pedagógico escrito que permitisse aos jovens alunos a reflexão sistematizada de conteúdos para avaliação dos sentidos da sua aprendizagem é um possível caminho, desde que assuma para isso os desafios do planejamento participativo (que toma o jovem aluno como interlocutor), uma discussão emancipatória de saberes, que aparece como uma dimensão inalienável da educação escolar com as juventudes contemporâneas, o que encontra inspiração em Arendt (2011) e Gómez (1998).

Vale o alerta de Dubet (PERVALVA; SPOSITO, 1997, p. 231, grifos nossos) de que:

0 problema é que não se sabe o que determina o efeito professor. 0 método pedagógico escolhido não faz a diferença. Os homens não são mais eficientes que as mulheres, os antigos não mais que os novos. Há velhos professores totalmente ineficientes e pessoas que começam eficientes logo na primeira semana. A ideologia do professor também não tem nenhum efeito. $O$ único elemento que parece desempenhar um papel é o efeito pigmaleão, isto é, os professores mais eficientes são em geral aqueles que acreditam que os alunos podem progredir, aqueles que têm confiança nos alunos. Os mais eficientes são também os professores que veem os alunos como eles são e não como eles deveriam ser. Ou seja são os que partem do nivel em que os alunos estão e não aqueles que não param de medir a diferença entre o aluno ideal e o aluno de sua sala. Mas, evidentemente, nas atitudes particulares, entram também orientações culturais gerais, interesses sociais, tipos de recrutamento e de formação. Não são apenas problemas psicológicos.

A leitura de Benjamin (1987) sobre Experiência e Pobreza e de Bondía (2002) denominada de Notas sobre a experiência e o saber da experiência são fundamentais para compreensão da realidade contraditória de ensino da EF no EM. 0 que faz parafrasear o questionamento de Benjamin: pois qual o valor de todo o nosso patrimônio cultural corporal de movimento para as juventudes, se a experiência pedagógica vivenciada na aula de EF parece não mais o vinculá-lo a nós? 
Benjamin (1987) enfatiza a pobreza da experiência quando reduzida ao individual, ao descartável, sem enraizamento no passado ou em uma perspectiva de futuro. A riqueza das experiências expressivas com o corpo em movimento é possibilitada pela organização pedagógica e infraestrutural. Elas encontram lugar nos diferentes projetos artísticos com engajamentos dos jovens alunos em ações culturais, movidas pela perspectiva do protagonismo juvenil, mas que parecem não encontrar tempo e espaço para ocorrência na aula de EF no EM.

A EF que se faz parece não enxergar outras possibilidades pedagógicas existentes nos arredores do Complexo Esportivo, que poderiam possibilitar a tematização de elementos das culturas juvenis como basquete de rua, skate, le parkur, entre outros. Para tanto, precisaria descentralizar o seu olhar acerca do espaço como foi construído, a fim de buscar um lugar para inclusão das culturas jovens no currículo da EF, explorando o espaço para outros usos, que não sejam aqueles implícitos à sua estrutura física, mas reinventados como práticas ordinárias do mundo jovem.

Fez-se o diagnóstico da constante e sintomática pobreza de fazer pedagógico do professor de EF. Trata-se de uma pobreza nas formas de relacionamento e comunicação com as juventudes, uma pobreza de função pedagógica, uma pobreza da imagem do professor de EF caracterizada pela lógica de regulação do espetáculo, agravada pela falta de mistério da e sobre a aula.

A aula de EF no EM limitou-se ao oferecimento de algumas experiências com o esporte - em modalidades tradicionais como futebol, vôlei e handebol - que discursivamente apregoam a perspectiva da inclusão, sem enxergar as diversas outras formas de poder e exclusão dos jovens alunos. Essas aulas acabam por se (re)produzir no cotidiano ordinário da aula, que podem ser compreendidas como dimensões de um currículo oculto; privilegiam experiências com o esporte que emitem sinais de saturação e esgotamento ao serem propostas tal como aquilo que os jovens alunos vivenciaram ao longo do Ensino Fundamental. Trata-se de aulas que insistem na exclusividade dos esportes de quadra ou de algumas poucas linhas teóricas arbitrárias, que por si só pouco dizem e conversam com as experiências corporais, dos jovens alunos em suas realidades sociais e culturais.

A aula de EF no EM se bastou a si mesmo, sem a ligação entre um episódio pedagógico e outro, apesar da alternância de espaços físicos para sua ocorrência. A aula é inexoravelmente ambígua, na produção de significações que possibilitem um encadeamento de saberes críticos sobre as práticas corporais às juventudes ou na contribuição para o processo de transformação de atitudes e comportamentos que possam referenciar o exercício da cidadania, como se propõe no Projeto Pedagógico da escola e no Planejamento de Ensino da disciplina.

Esse modus operandi informa acerca de uma situação de busca pedagógica pela qualificação das experiências escolares na vida dos jovens alunos, em especial, nas aulas de EF no EM que faça a leitura dos corpos jovens com que lida, suas demandas e interesses. $\mathrm{Na}$ acepção de Maffesoli (1987) acerca das tribos juvenis, isso assinalaria que o desafio posto à escola e à EF para as juventudes é buscar a compreensão do dinamismo societal a partir da investigação da centralidade subterrânea das experiências sociais, corporais e sensíveis ao jovem. Portanto, que carece observar os recreios, os pátios e os cotidianos 
escolares habitados pelos jovens, para que possa aproximar das práticas corporais do universo juvenil, num movimento de ligação com o jovem, que parece necessário para que ocorra a legitimidade e autonomia pedagógica da disciplina no currículo do EM.

Não se advoga em prol de uma ação educativa que não considere as tensões sociais e econômicas, que tangenciam o projeto de escolarização das massas, e que tampouco se negue a reconhecer as culturas juvenis e suas formas de linguagem, pois é impossível separar o mundo da vida do mundo da escola. Trata-se de defender práticas que se assemelhem a uma educação dotada de sentidos, uma conexão significativa entre os acontecimentos pedagógicos e não meramente informativa, como nos propõem Benjamin (1987) e Bondía (2002).

Essas questões são, foram e continuam sendo discutidas pelo pensamento progressista brasileiro da EF. Com o devido peso do relativismo, que rejeita uma linearidade das práticas escolares, percebeu-se que a EF, do ponto do vista do planejamento de ensino, sabe até o que fazer; porém no cotidiano, as intenções do planejamento de ensino não se concretizam e se esfumaçam, pois seguem desvinculadas da vida das escolas onde se materializam as práticas pedagógicas da EF (CAPARROZ; BRACHT, 2007). Ou seja, não contribuem para superar o quadro reincidente, parafraseando Bauman, de mal-estar da EF no EM, ou seja, de desinvestimento pedagógico que beira o abandono à docência.

\section{Considerações transitórias}

0 estudo registra a necessidade de aproximação dos mundos da escola do mundo das juventudes, a partir do reconhecimento da condição juvenil do jovem aluno do EM que está jovem, em uma fase singular da vida, em que se processam preocupações e angústias da trajetória pessoal, da vida escolar, da preparação para o mundo do trabalho, da transição para vida adulta.

É condição para o alcance dessas metas o compartilhar de práticas curriculares e pedagógicas que têm por meta o desenvolvimento individual do aluno, a partir da construção da sua autonomia crítica intelectual, com a atribuição de sentidos às práticas culturais e sociais vividas individual ou coletivamente, no cotidiano escolar. 0 que também se aplica a EF no EM da escola campo de investigação.

Os problemas da prática pedagógica da EF no EM estão no desconhecimento da cultura escolar que permeia a ação pedagógica e na (in)visibilização de uma dinâmica curricular e pedagógica que se abram para as práticas corporais do mundo jovem, tematizando-as para além do simples fazer, mas em direção ao que asseveramos como: perspectiva educativa cada vez mais próxima daquilo em que "se sabe o que se faz com o corpo”. Isso nos faz sugerir a importância da reflexão de práticas pedagógicas que valorizem o ensino das práticas corporais a partir da aproximação com o universo juvenil, a fim de legitimar a presença da EF no currículo do EM.

\section{Referências}

ALMEIDA, Felipe Quintão de. Educação física escolar e práticas pedagógicas inovadoras: uma revisão. Corpoconsciência, Cuiabá, v. 21, n. 03, p. 7-16, set./dez. 2017. 
ARENDT, Hannah. Entre o passado e o futuro. Tradução Mauro V. Barbosa. 7. ed. São Paulo: Perspectiva, 2011. BAUMAN, Zygmunt. 44 cartas do mundo líquido moderno. Tradução Vera Pereira. Rio de Janeiro: Zahar, 2011. BENJAMIN, Walter. Obras escolhidas: magia e técnica, arte e política. 3. ed. São Paulo: Brasiliense, 1987. BOGDAN, Robert C.; BIKLEN, Sari K. Investigação qualitativa em educação: uma introdução à teoria e aos métodos. Porto: Porto Editora, 1994.

BONDÍA, Jorge Larrosa. Notas sobre a experiência e o saber da experiência. Revista Brasileira de Educação, Campinas, n. 19, p. 20-28, 2002.

BRASIL. Ministério da Educação. Lei n 10.793, de 01 de dezembro de 2003. Altera a redação do art. 26, par. $3^{\circ}$, e do art. 92 da lei 9.394, de 20 de dezembro de 1996, que "estabelece as diretrizes e bases da educação nacional", e dá outras providências. Brasília, DF: MEC, 2003. Disponível em: https://legislacao. presidencia.gov.br/atos/?tipo=LEl\&numero=10793\&ano=2003\&ato=76903a610dRpWTb15. Acesso em 12 jan. 2021.

BRASIL. Ministério da Educação. Resolução no. 2/2012 da CEB/CNE. Diretrizes Curriculares Nacionais para o Ensino Médio. Brasília, DF: CNE, 2012.

BRASIL. Ministério da Educação. Secretaria de Educação Média e Tecnológica. Orientações curriculares para 0 ensino médio. Brasília, DF: MEC, 2006.

BUNGENSTAB, Gabriel Carvalho e colaboradores. Educação física no ensino médio: possibilidades de ensino das práticas corporais. Corpoconsciência, Cuiabá, v. 21, n. 3, p. 29-40, set./dez. 2017.

CAPARROZ, Francisco Eduardo. Entre a educação física da escola e a educação física na escola: a educação física como componente curricular. Vitória: UFES; Centro de Educação Física e Desportos, 1997.

CAPARROZ, Francisco Eduardo; BRACHT; Valter. 0 tempo e o lugar de uma didática da educação física. Revista Brasileira de Ciências do Esporte, Campinas, v. 28, n. 2, p. 21-37, jan. 2007.

CARRANO, Paulo Cesar Rodrigues. A participação social e política de jovens no Brasil: considerações sobre estudos recentes. 0 Social em Questão, Rio de Janeiro, v. 15, n. 27, p. 83-100, 2012.

COFFANI, Márcia Cristina Rodrigues da Silva et al. Problematizações para uma prática pedagógica inovadora da educação física no ensino médio. Corpoconsciência, Cuiabá, v. 22, n. 03, p. 101-114, set./dez., 2018.

DAYRELL, Juarez Tarcísio. 0 aluno do ensino médio: o jovem desconhecido. Boletim Salto para o Futuro, Ministério da Educação, Secretaria de Educação a Distância, v. 19, n. 18, p.16-23, nov. 2009. Temática juventude e escolarização: os sentidos do ensino médio.

DAYRELL, Juarez Tarcísio; GOMES, Nilma Lino; LEÃO, Geraldo. Escola e participação juvenil: é possível esse diálogo? Educar em Revista, Curitiba, n. 38, p. 237-252, set./dez. 2010. 
DAYRELL, Juarez Tarcísio et al. Juventude e escola. In: SPOSITO, Marilia Pontes. Estado da arte sobre juventude na pós-graduação brasileira: educação, ciências sociais e serviço social (1999-2006). v.1. Belo Horizonte: Argvmentvm, 2009. p. 57-126.

ELIAS, Norbert; SCOTSON, John L. Os Estabelecidos e os outsiders: sociologia das relações de poder a partir de uma pequena comunidade. Rio de Janeiro: Jorge Zahar: 2000.

FENSTERSEIFER, Paulo Evaldo; SILVA, Marlon André da. Ensaiando o "novo" em educação física escolar: a perspectiva de seus atores. Revista Brasileira de Ciências do Esporte, Porto Alegre, v. 33, n. 1, p. 119-134, jan. /mar. 2011.

FONSECA, Cláudia, Quando cada caso NÃO é um caso. Revista Brasileira de Educação, Rio de Janeiro, n. 10, p. 58-78, jan./abr. 1999.

GOMÉZ, Angel I. Pérez. As funções sociais da escola: da reprodução à reconstrução crítica do conhecimento e da experiência. In: SACRISTÁN, J. Gimeno; GOMÉZ, Angel I. Pérez. Compreender e transformar o ensino. 4. ed. Porto Alegre: Artmed, 1998. p. 13-26.

KRAWCZYK, Nora. Uma roda de conversa sobre os desafios do ensino médio. In: DAYRELL, Juarez Tarcísio; CARRANO, Paulo Cesar Rodrigues; MAIA, Carla Linhares (org.). Juventude e ensino médio: sujeitos e currículos em diálogo. Belo Horizonte: UFMG, 2014. p. 75-98.

LÜDKE, Menga; ANDRÉ, Marli Eliza Dalmazo Afonso. Pesquisa em educação: abordagens qualitativas. São Paulo: Pedagógica e Universitária, 1986.

MAFFESOLI, Michel. 0 Tempo das tribos: 0 declínio do individualismo nas sociedades de massa. Rio de Janeiro: Forense Universitária, 1987.

PERALVA, Angelina Teixeira; SPOSITO, Marilia Pontes. Quando o sociólogo quer saber o que é ser professor. Entrevista com François Dubet. Revista Brasileira de Educação, São Paulo, n. 5/6, p. 222-231, maio/ dez. 1997.

SILVA, Marlon André da Silva; SILVA, Lisandra Oliveira e Silva; MOLINA NETO, Vicente. Possibilidades da educação física no ensino médio técnico. Movimento, Porto Alegre, v. 22, n. 1, 325-336, jan./mar. 2016.

TABORDA DE OLIVEIRA, Marcus Aurélio et al. Práticas de professores escolares como possibilidade de pensar e fazer da escola um lugar de cultura: são possíveis boas práticas educativas? 59f. Relatório de pesquisa. Curitiba: [s. n.], 2008.

Recebido em: 07.10.2019

Revisado em: 03.12.2019

Aprovado em: 18.02.2020 
Márcia Cristina Rodrigues da Silva Coffani é licenciada em Educação Física; mestre e doutora em Educação e professora adjunto II da Faculdade de Educação Física da Universidade Federal de Mato Grosso (UFMT).

Cleomar Ferreira Gomes é doutor em Educação; pós-doutor em socioantropologia em Educação e professor titular da Faculdade de Educação Física da Universidade Federal de Mato Grosso (UFMT). 